\title{
Boundary Conditions of Flow Transition Model for Roughened Surface
}

\author{
Son, Chankyu; Kim, Taeseong
}

Published in:

AIAA Journal

Link to article, DOI:

10.2514/1.J060641

Publication date:

2022

Document Version

Peer reviewed version

Link back to DTU Orbit

Citation (APA):

Son, C., \& Kim, T. (2022). Boundary Conditions of Flow Transition Model for Roughened Surface. AIAA Journal, 60(1). https://doi.org/10.2514/1.J060641

\section{General rights}

Copyright and moral rights for the publications made accessible in the public portal are retained by the authors and/or other copyright owners and it is a condition of accessing publications that users recognise and abide by the legal requirements associated with these rights.

- Users may download and print one copy of any publication from the public portal for the purpose of private study or research.

- You may not further distribute the material or use it for any profit-making activity or commercial gain

- You may freely distribute the URL identifying the publication in the public portal

If you believe that this document breaches copyright please contact us providing details, and we will remove access to the work immediately and investigate your claim 


\title{
Boundary Conditions of Flow Transition Model in Reynolds- Averaged Navier-Stokes Equations for Roughened Surface
}

\author{
Chankyu Son ${ }^{1}$ \\ Cheongju University, Cheongju, 28503, Republic of Korea \\ and \\ Taeseong Kim ${ }^{2}$ \\ Technical University of Denmark, Kongens Lyngby, 2800, Denmark \\ Loughborough University, Loughborough, LE11 3TT, UK
}

\section{Nomenclature}

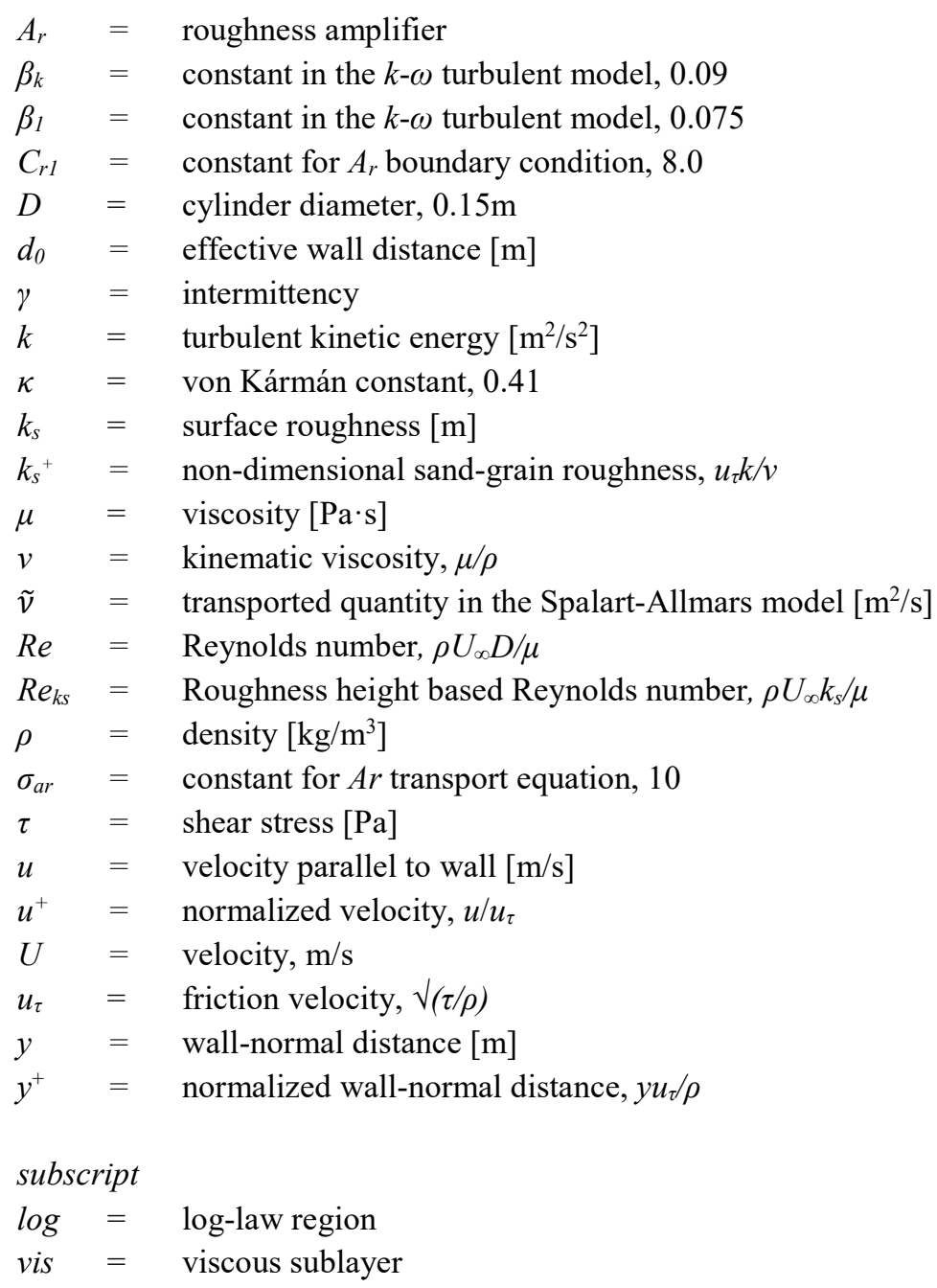

\footnotetext{
${ }^{1}$ Assistant Professor, Department of Unmanned Aircraft Systems, and AIAA Member for first author, cson@cju.ac.kr

${ }^{2}$ Professor, Wind Energy, and AIAA Member for corresponding author, tkim@dtu.dk
} 
$\infty \quad=\quad$ freestream

$1=$ value of the wall-adjacent cell

\section{Introduction}

IMULATIONS based on Reynolds-Averaged Navier-Stokes consider the flow transition induced by surface roughness by adding or modifying transport equations and boundary conditions in a turbulence model. Langtry and Menter [1] suggested a flow transition model by adding an intermittency $(\gamma)$ equation that is coupled with the shear stress transport (SST) $\mathrm{k}-\omega$-based turbulence model [2]. It is called the $\gamma-\operatorname{Re}_{\theta}$ model with which the flow transition onset, as well as the distribution of skin friction on smooth surfaces, are successfully predicted.

A transport equation called 'roughness amplification' $\left(A_{r}\right)$ was added into the $\gamma-R e_{\theta}$ model to effectively consider the flow transition induced by surface roughness [3]. Thereafter, Langel et al. [4] refined the roughness amplification method through a blending function to prevent the unphysical undershoot in the transition onset criterion. However, both turbulence models using roughness amplification $[3,4]$ did not have any boundary conditions to model the increased turbulent kinetic energy $(k)$ and turbulence eddy viscosity $\left(\mu_{t}\right)$ on the rough wall. It results in distorting the flow field around the circular cylinder because the turbulence models based on RANS equations consider the surface roughness effects as increasing turbulence viscosity $\left(\mu_{t}\right)$ at the wall instead of treating the detailed roughness elements.

On the other hand, the increased turbulence viscosity induced by surface roughness has been correlated through boundary conditions for decades. Recently, Knopp et al. [5] suggested the boundary conditions for both $k$ and $\omega$ (turbulence dissipation rate) to consider the surface roughness for $k$ - $\omega$-based turbulence models. In their boundary conditions, the non-zero turbulence viscosity can be determined by the following definition: $\mu_{t}=k / \omega$. However, the feasibility of the boundary conditions for $k$ and $\omega$ were unclear where the flow transition is expected because their boundary conditions were derived from the fully turbulent assumption.

Son et al. [6] coupled both approaches related to boundary conditions and transport equations for the RANS-based turbulence model to predict the flow transition induced by surface roughness. They applied the boundary conditions suggested by Knopp et al. [5] into the turbulence model using the roughness amplification model suggested by Langel et al. [4]. They discovered that the roughness amplification model can predict the transition onset and the distributions of skin friction on the roughened circular cylinder only when the turbulence model was coupled with the boundary conditions of $k$ and $\omega$ [6]. 
Although the coupled method of transport equations and boundary conditions to explain the flow transition induced by surface roughness yielded accurate results, the proposed correlations for $k$ and $\omega$ boundary conditions are ad hoc attempts. For example, Knopp et al. [5] employed the effective wall distance to consider the surface roughness suggested by Spalart [7]. Spalart-Allmaras turbulence model considers the surface roughness by imposing an offset $d=d_{\text {clean }}+d_{0}$, where $d_{\text {clean }}$ is the distance of the clean surface and $d_{0}$ is the effective wall distance to account for the surface roughness. By using the effective wall distance, Spalart-Allmaras turbulent model was successfully extended to explain the surface roughness. However, the effective wall distance $\left(d_{0}\right)$ was assumed under the fully-turbulent and fully-roughened surface. Consequently, the effective wall distance for $k$ and $\omega$ boundary conditions should be adjusted by using blending functions to explain the effect of roughness height: relatively smooth, transitional rough, and fully rough surfaces. However, the limits or applicable range of these blending functions are not yet known, because the correlations were derived from the limited numbers of experimental data.

To this end, this study presents the efforts to derive rigorous boundary conditions for $k$ and $\omega$ over the roughened surface. An effective wall distance and automatic wall treatment instead of considering various surface roughness heights based on physical models are introduced. The distributions of skin friction on the flat plate and roughened circular cylinder computed with the suggested method are compared with the existing method that uses the blending functions for $k$ and $\omega$ boundary conditions.

\section{Flow Transition model for the roughed surface}

\section{A. Transport equation}

The flow transition induced by surface roughness was introduced by Langel et al. [4] by adding a transport equation called roughness amplifier $\left(A_{r}\right)$ with the $\gamma-R e_{\theta}$ model [1] as shown in Eq. (1):

$$
\frac{\partial\left(\rho A_{r}\right)}{\partial t}+\frac{\partial\left(\rho U_{j} A_{r}\right)}{\partial x_{j}}=\frac{\partial}{\partial x_{j}}\left[\sigma_{a r}\left(\mu+\mu_{t}\right) \frac{\partial A_{r}}{\partial x_{j}}\right]
$$

where the constant $\sigma_{a r}$ is 10 . The roughness amplification controls the source term of the transport equation for the local momentum thickness. According to the increased local momentum thickness, the flow transition can be triggered early. The roughness is also considered within the boundary condition of $A_{r}$, which is a function of the non-dimensional sand-grain roughness $\left(k_{s}{ }^{+}=\rho u_{\tau} k_{s} / \mu\right)$ :

$$
\left.A_{r}\right|_{\text {wall }}=C_{r 1} k_{s}^{+}
$$


Here, $\rho, u_{\tau}, k_{s}$, and $\mu$ are density, friction velocity, surface roughness, and viscosity, respectively. By following Langel et al. [4], this study applies 8.0 for the constant $C_{r l}$. The roughness amplifier method effectively explains the surface roughness for the flow transition. More details about this transition model can be found in the references $[4,6]$.

\section{B. Boundary conditions}

Meanwhile, the wall boundary conditions to consider the surface roughness for $k$ - $\omega$ based turbulence models were suggested. The wall value of $k$ should be equivalent to that in a fully developed turbulent flow. The wall value of $k$ proposed by Knopp et al. [5] is written in Eq. (3):

$$
k_{\text {wall }}=k_{\text {rough }} \varphi_{r 1}
$$

The $k_{\text {rough }}$ value is suggested by Durbin et al. [8] and it is assumed for the fully rough surface as shown in Eq. (4) with $\beta_{k}=0.09$

$$
k_{\text {rough }}=\left(\frac{u_{\tau}^{2}}{\sqrt{\beta_{k}}}\right)
$$

Since the $k_{\text {rough }}$ is derived from the fully roughened surface, the blending function shown in Eq. (5), $\varphi_{r l}$, is applied to cover the various roughness heights. Knopp et al. [5] assumed that the $k$ value is linearly proportional to the roughness height $\left(k_{s}^{+}\right)$. Thus, the blending function $\varphi_{r l}$ reduces the $k_{\text {wall }}$ value for a hydraulically smooth or transitionally roughened surface where the surface has the low roughness height,

$$
\varphi_{r 1}=\min \left(1, \frac{k_{s}^{+}}{90}\right)
$$

The $\omega$ boundary condition at walls is also modified as written in Eq. (6) where the von Kármán constant $(\kappa)$ is 0.41

$$
\omega_{\text {wall }}=\left(\frac{u_{\tau}}{\kappa d_{0} \sqrt{\beta_{k}}}\right)
$$

The $d_{0}$ in Eq. (7) plays the same role as the effective distance due to the surface roughness in Spalart-Allmaras turbulence models suggested by Aupoix and Spalart [9]. Here, $0.03 k_{s}$ means that the effective distance $\left(d_{0}\right)$ is induced by the surface roughness at the fully roughened surface

$$
\begin{gathered}
d_{0}=\varphi_{r 2} 0.03 k_{s} \\
\varphi_{r 2}=\min \left[1,\left(\frac{k_{s}^{+}}{30}\right)^{\frac{2}{3}}\right] \min \left[1,\left(\frac{k_{s}^{+}}{45}\right)^{\frac{1}{4}}\right] \min \left[1,\left(\frac{k_{s}^{+}}{60}\right)^{\frac{1}{4}}\right] .
\end{gathered}
$$


In order to consider the smooth and transitionally roughened surface, the blending function $\varphi_{r 2}$ (see Eq. (8)) is also employed for the $\omega$ boundary condition.

\section{Modified boundary conditions}

From the previous study [5] the boundary conditions could be extended into the flow transition model although the boundary conditions were derived under the fully turbulent assumption. Moreover, the surface roughness was considered as the fully roughened surface. In order to adjust the effects of roughness height the blending functions as shown in Eqs. (3) and (7) are applied. However, the blending functions were derived only from limited numbers of experimental data obtained with flat plates. Therefore, the proposed model has a physical limitation to consider various surface roughness types.

In this study, a rigorous model based on physical observations is introduced which is able to faithfully consider the various surface types: relatively smooth, transitional-rough, and fully-rough surface. First of all, the velocity profile according to the roughness height is considered. It is well known that turbulent boundary layers over rough walls satisfy the log-law layer of the wall with a certain amount of shift [10]. The velocity profile over rough walls can be described by the following equation:

$$
\frac{u}{u_{\tau}}=\frac{1}{\kappa} \ln \left(\frac{y}{k_{s}}\right)+B
$$

where the value of $B$ varies with the height of roughness $\left(k_{s}\right)$.

Aupoix et al. [9] suggested effective wall distance $\left(d_{0}\right)$ for the fully rough surface as

$$
\frac{y+d_{0}}{d_{0}}=\frac{y}{k_{s}} e^{\kappa B},
$$

where $y$ is the wall distance of the first cell center to the wall. This relation was derived from Eq. (10) with transported quantity $(\tilde{v})$ in the Spalart-Allmaras model. The transported quantity $(\tilde{v})$ equals to the turbulence kinematic viscosity $\left(v_{t}\right)$ [9]. On the fully rough surface, Aupoix and Spalart applied the following assumption: $y>>d_{0}$ [9] for RANS simulation. This assumption is not required for LES or DNS simulations. In general, the grid for RANS simulation requires reasonably large $y$. Moreover, for the fully roughened surface, $d_{0}$ is $0.03 k_{s}$ which is an extremely small value. Therefore $y>>d_{0}$ assumption is valid for RANS.

When applying $B=8.5$ proposed by Nikuradse [10] for the fully roughened pipe flow, the effective wall distance becomes 


$$
d_{0}=\exp (-B \kappa) k_{s}=0.03 k_{s}
$$

As mentioned above, the blending functions are required to reduce or adjust $d_{0}$ value for the various roughness height. However, this study computes the variable function $B$ according to the roughness height unlike using the constant value 8.5 observed from the fully roughened pipe flow.

Ligrani and Moffat [11] suggested a model to quantitatively explain the shift of velocity profile according to the roughness height as

$$
B=\left[C+\frac{1}{\kappa} \ln \left(k_{s}^{+}\right)\right]\left(1-\sin \left(\frac{\pi g}{2}\right)\right)+8.5 \sin \left(\frac{\pi g}{2}\right) .
$$

They included function $g$ that can consider the roughness height: smooth $\left(k_{s}{ }^{+}<k_{r, S}{ }^{+}\right)$, transitional $\operatorname{rough}\left(k_{r, S}{ }^{+}<k_{s}{ }^{+}<k_{r, R}{ }^{+}\right)$, and fully rough $\left(k_{s}^{+}>k_{r, R}{ }^{+}\right)$surfaces [11]. The values $k_{s}^{+}, k_{r, R}{ }^{+}$, and $k_{r, S}{ }^{+}$depend on the roughness-geometry characteristics. For sand-grain roughness, Ligrani and Moffat [11] proposed $k_{r, S}{ }^{+}=2.25$ and $k_{r, R}{ }^{+}=90$. Therefore, the function $B$ to obtain the effective roughness distance, $d_{0}=\exp (-B \kappa) k_{s}$, can be directly calculated instead of using $0.03 k_{s}$ suggested by Nikuradse [10], where the function $g$ is defined as follows:

$$
g=\left\{\begin{array}{ll}
\frac{\ln \left(\frac{k_{S}{ }^{+}}{k_{r, S}}\right)}{\ln \left(\frac{k_{r, R}{ }^{+}}{k_{r, S}}\right)}: & k_{r, S}^{+}<k_{S}^{+}<k_{r, R}{ }^{+} \\
1 & : k_{S}^{+}>k_{r, R}^{+} \\
0 & : k_{S}^{+}<k_{r, S}^{+}
\end{array} .\right.
$$

The velocity profile in Eq. (9) is valid in the logarithmic part of turbulent boundary layers. Therefore, the velocity profile obtained in the log-law layer can distort the wall roughness effects for the small roughness height, underresolved grids, or low Reynolds numbers. To avoid the deterioration of the results induced by the small roughness height and coarse-grid resolution, the specific near-wall treatment suggested by Menter et al. [12] is applied for this study. The boundary condition called automatic wall treatment is suggested for $k-\omega$ SST turbulence models. It is reported that the automatic wall treatment is virtually moved down the location of the near-wall grid node by blending values of the viscous sublayer and the log-law layer for $u_{\tau}$ and $\omega$ [13].

For the $k$ boundary condition, the friction velocity defined by the definition: $u_{\tau}=\left(\tau_{w} / \rho\right)^{1 / 2}$ is replaced by the new friction velocity $\left(u_{\tau, \text { new }}\right)$ suggested by Menter et al. [12]. It can be smoothly blended for the viscous sublayer, buffer layer, and log-law layer as follows:

$$
u_{\tau, \text { new }}=\sqrt[4]{u_{\tau, v i s}^{4}+u_{\tau, \log }^{4}} .
$$


The friction velocities in the viscous sublayer and the log-law layer are determined in terms of the velocity and $y^{+}=$ $\rho y u_{\tau} / \mu$ at the wall-adjacent cell as written in Eq. (15). For the viscous sublayer, the surface roughness is considered by adding the non-dimensionalized effective wall distance $\left(d_{0}{ }^{+}=\rho d_{0} u_{\tau} / \mu\right)$ as $y^{+}+d_{0}{ }^{+}$. For the log-law layer, the same assumption with Aupoix et al. [9] as mentioned in Eqs. (9) and (10) is applied

$$
u_{\tau, v i s}=\frac{u_{1}^{+}}{d_{0}{ }^{+}+y^{+}} ; u_{\tau, \log }=\frac{u_{1}{ }^{+}}{\frac{1}{\kappa} \ln \left(\frac{d_{0}+y^{+}}{d_{0}{ }^{+}}\right)} .
$$

A similar approach with the velocity profile is also applied for the $\omega$ boundary condition as written in Eq. (16)

$$
\omega_{\text {new }}=\sqrt{\omega_{\text {vis }}^{2}+\omega_{\log ^{2}}} .
$$

The $\omega$ boundary conditions are also combined by the values for the viscous sublayer and the log-law layer as

$$
\omega_{\text {vis }}=\frac{6}{\beta_{1}\left(d_{0}{ }^{+}+y^{+}\right)^{2}} ; \omega_{\log }=\frac{1}{\kappa \sqrt{\beta_{\mathrm{k}}\left(d_{0}{ }^{+}+y^{+}\right)}},
$$

where $\beta_{1}=0.075$.

\section{Results and Discussion}

As described above, the present boundary conditions for $k$ and $\omega$ do not require any blending function for considering the various roughness heights. The effective wall distance explains the shift of velocity profile on the rough wall. The analytically driven $u_{\tau}$ and $\omega$ are applied for both the viscous sublayer and log-law layer [13].

The suggested method is validated and compared with a flat plate [14] based on the Reynolds number $\left(R e_{x}=\rho U x / \mu\right)$, where $x$ is the distance from the leading edge of the plate. The freestream velocity and length of plate are set to be 15 $\mathrm{m} / \mathrm{s}$ and $1.3 \mathrm{~m}$, respectively. Consequently, numerical simulations are performed under the distance-based $\operatorname{Re}_{x}$ of $1.3 \times 10^{6}$. The turbulent freestream intensity of $0.9 \%$ is applied $[3,4]$.

Figure 1 shows the transition onset Reynolds numbers $\left(R e_{x t}\right)$ over the equivalent sand grain roughness height Reynolds number $\left(\operatorname{Re}_{k s}=\rho U k_{s} / \mu\right)$. The various existing numerical results using the roughness amplifier are depicted with the measured data [14]. The present method is also over-plotted with the red circle solid line. It reveals that the proposed method predicts transition points very well compared to existing experimental and numerical results [3, 4, $6,14]$. 


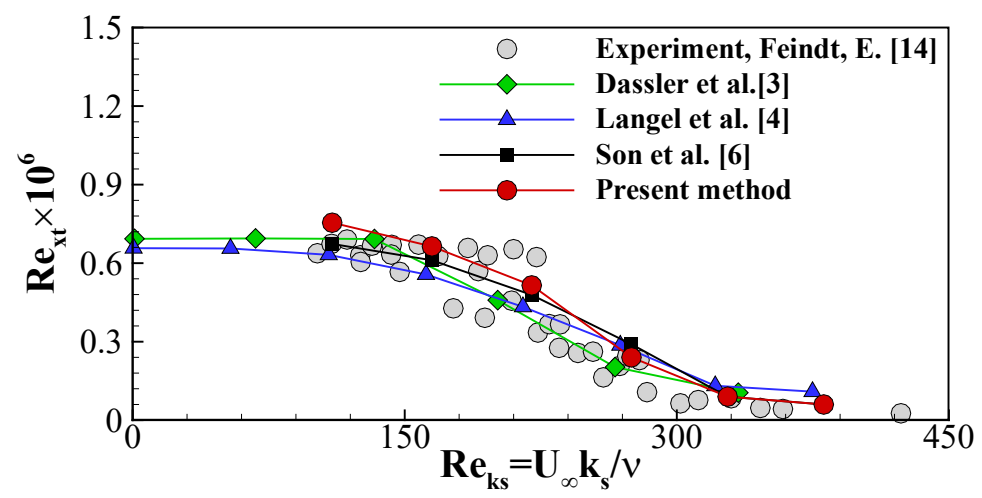

Fig. 1 Tradition onset on the flat plate with the various surface roughness

Figure 2 shows the skin friction coefficients on roughened flat plate surface with various roughness $R e_{k s}$. Numerical results obtained by the present method (solid lines), Dassler et al. [3] (circular points), and Son et al. [6] (dashed lines) are compared. In Fig. 2, it is confirmed that the present method predicts the transition point very well for various surface roughness cases. Especially, the skin friction distributions are very similar for the fully roughened surface $\left(\operatorname{Re}_{\mathrm{ks}}>220\right)$. However, the transition points are predicted slightly earlier than other numerical results for the relatively smooth surface condition $\left(\operatorname{Re}_{\mathrm{ks}} \leq 220\right)$.

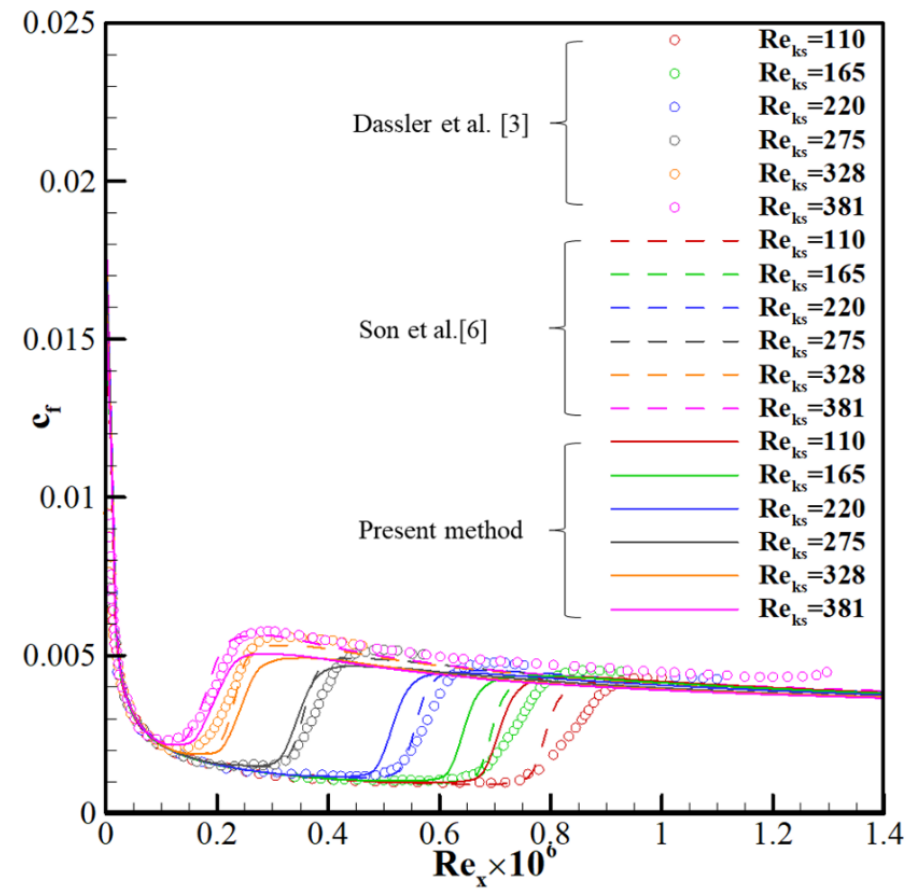

Fig. 2 Distributions of skin friction on the flat plate with the various surface roughness 
In order to evaluate the different performances of the skin friction in the low $R e_{k s}$ conditions, the function $B$ in Eq. (9) is analyzed. As mentioned above, the function $B$ explains the amount of shifted value of the velocity profile induced by surface roughness. The previous studies [5,9] derived the function $B$ with the fully roughened surfaces under the fully turbulent conditions. A constant value of $B=8.5$ is often applied regardless of the surface roughness height. Therefore, the accuracy of the solution very depends on the surface roughness. On the other hand, the present study directly computes the function $B$ according to the roughness height by Ligrani and Moffat [11]. It does not require any blending correlations for $k$ and $\omega$ boundary conditions. Fig. 3 shows the function $B$, the shift of velocity profile, due to the surface roughness. There is a difference of the function $B$ between the other numerical models $[5,9]$ and the present method. The boundary conditions suggested by Knopp et al. [5] tend to significantly overpredict $B$ in the region with small surface roughness. In addition, the overall B distribution is higher than the experiment [10]. On the other hand, the distribution of B predicted by the proposed method is well matched with the experiment [10].

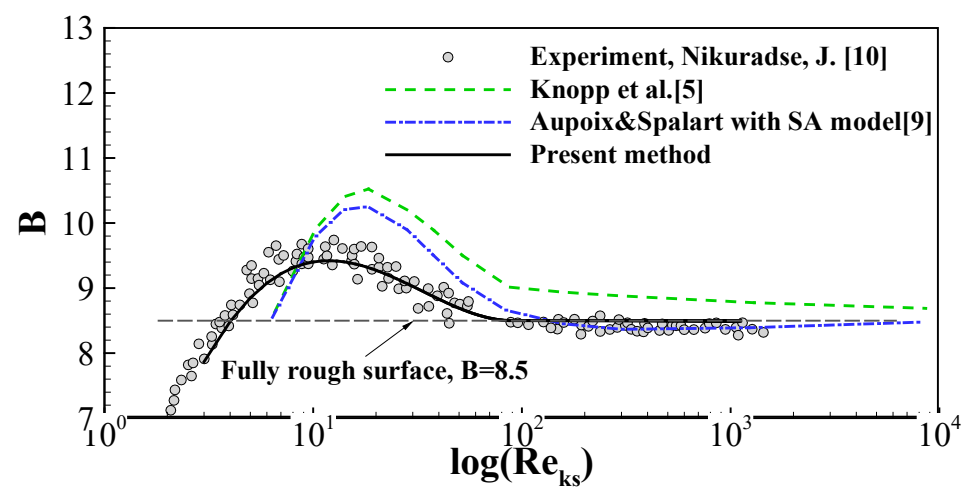

Fig. 3 The shifted velocity profile function B induced by surface roughness

There was an experimental approach to investigate the flow transition induced by surface roughness on a circular cylinder [14]. Using a pressurized wind tunnel, the distributions of skin friction were measured with various Reynolds numbers $\left(\operatorname{Re}=\rho_{\infty} U_{\infty} D / \mu_{\infty}\right)$ and roughness Reynolds numbers $\left(\operatorname{Re}_{k s}=\rho_{\infty} U_{\infty} k_{s} / \mu_{\infty}\right)$ where $\mu$, $\rho$, and $U$ are the viscosity, density, and velocity, respectively. A circular cylinder with a diameter $D=0.15 \mathrm{~m}$ and a span of $0.5 \mathrm{~m}$ was used for their experiment. The non-dimensionalized equivalent sand-grain roughness $\left(k_{s} / D\right)$ values were $110 \times 10^{-5}$ and $450 \times$ $10^{-5}$. For the numerical simulations, a spacing of $\Delta y / D=1.5 \times 10^{-6}$ for the first off-wall node (proposed by Knopp et al. [5]) is applied. 
To clearly show the improvement and limitation of the present turbulent model, simulations are performed for various Reynolds numbers. The validation conditions cover the laminar flow and fully-turbulent flow, including the flow transition. Fig. 4 shows the skin friction distributions obtained by the present method (solid line), Knopp et al. [5] (dashed line), and experiment (symbol) along with the roughened cylinder for the relatively smooth surface, $k_{s} / D=110 \times 10^{-5}$. The different trends of the skin friction distributions can be found in Fig. 3 with respect to Reynolds numbers. At $R e=1.3 \times 10^{5}$, laminar flow is maintained, but the flow transition can be observed for both numerical and experimental results at the higher $\operatorname{Re}\left(R e=4.3 \times 10^{5}\right.$ and $\left.R e=6.5 \times 10^{5}\right)$.

For the low surface roughness height, $k_{s} / D=110 \times 10^{-5}$, there are no noticeable changes in the distribution of skin friction regardless of $R e$ in the present and previous [5] methods. Both methods yield good agreement with the experimental data for various $R e$. In the laminar region, the present and Knopp et al. [5] methods are identical. However, at higher $\operatorname{Re}\left(\operatorname{Re}=4.3 \times 10^{5}\right.$ and $\left.R e=6.5 \times 10^{5}\right)$ where the flow transition occurs, the difference in the slope of skin friction at the transition onset region can be observed. Nevertheless, the peak values and positions of skin friction can be obtained almost the same regardless of the boundary conditions applied.

To show the effect of the surface roughness height, the distributions of skin friction on the relatively rough surface $\left(k_{s} / D=450 \times 10^{-5}\right)$ are also compared. Fig. 5 illustrates the distributions of the skin friction under the laminar, transient, and fully turbulent flow conditions. When higher surface roughness is applied, the discrepancies of skin friction between the two different boundary conditions (the present and Knopp et al. [5] methods) become more significant. In both laminar $\left(R e=1.0 \times 10^{5}\right)$ and fully turbulent $\left(R e=3.0 \times 10^{5}\right)$ conditions, the present method shows good agreement with the experimental results where the peak values and locations obtained by the present method are well predicted. On the other hand, the skin friction is overestimated in the laminar condition and underestimated in the fully turbulent condition with the blending functions [5].

The present method successfully predicts the distributions of skin friction and transition onset for the various $R e$ and $k_{s}$ without any empirical correlations such as the blending functions suggested by Knopp et al. [5]. Since the proper shift of velocity profile and the effective distance according to the roughness heights are considered, the properties for the viscous sublayer and the log-law layer are well blended for $u_{\tau}$ and $\omega$ boundary conditions.

The profile of $A_{r}$ is still unknown with respect to $k_{s}^{+}$. However, $A_{r}$ is generally assumed to be linearly proportional to the surface roughness height as written in Eq. (2). It affects the prediction of the transition onset position. For 
example, in the cylinder condition as shown in Figs. 4 and 5, the slightly delayed transition onset was observed. Therefore, various experimental studies to find rigorous $A_{r}$ boundary conditions are planned as a future work.

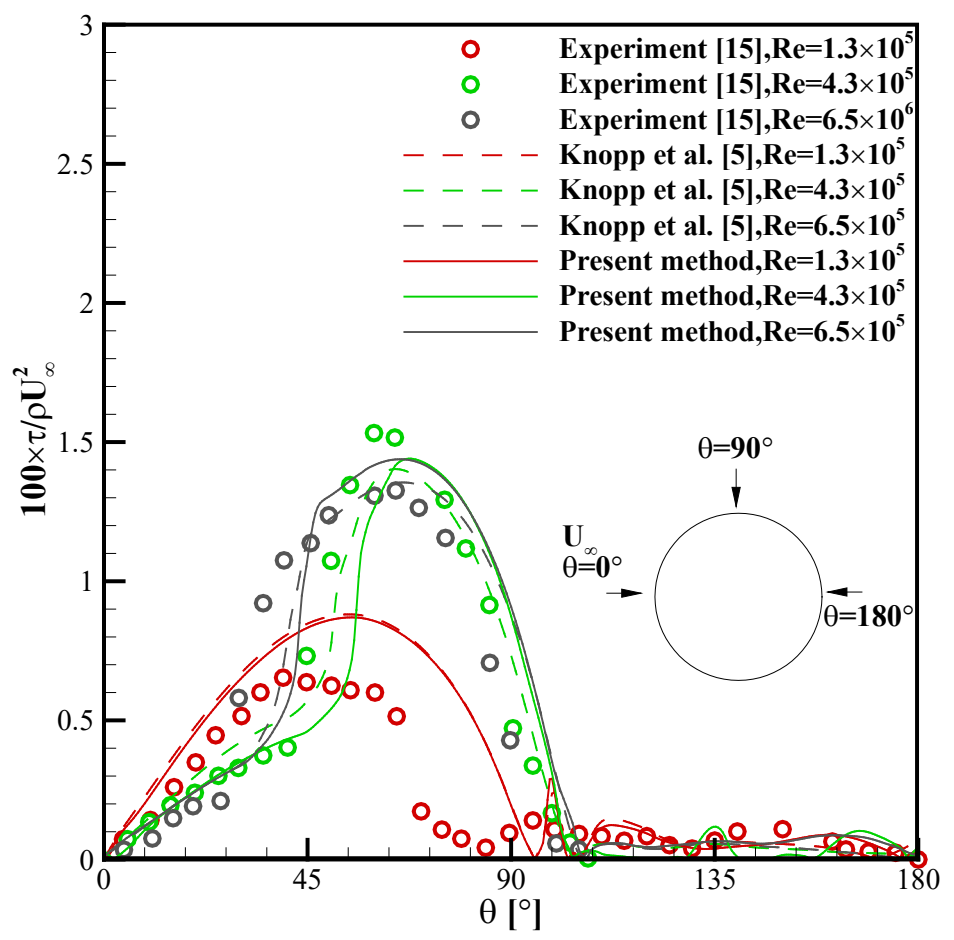

Fig. 4 Distributions of skin friction for the roughened circular cylinder $\left(k_{s} / D=110 \times 10^{-5}\right)$ 


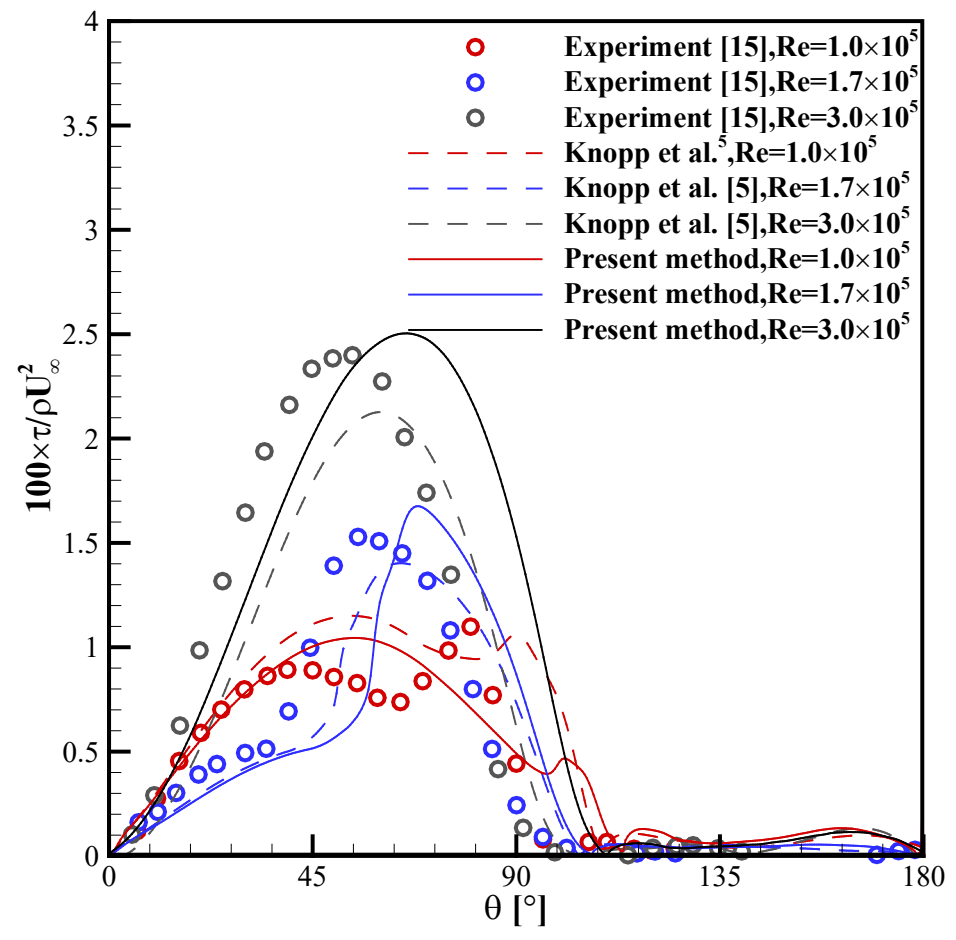

Fig. 5 Distributions of skin friction for the roughened circular cylinder $\left(k_{s} / D=450 \times 10^{-5}\right)$

\section{Conclusion}

In summary, this study introduces a rigorous model to consider the boundary conditions for the flow transition induced by surface roughness in RANS simulations. It does not require any ad hoc correlations for $k$ and $\omega$ boundary conditions unlike Knopp et al. [5]. To account for various wall roughness heights such as relatively smooth-, transitional-rough, and fully-rough surfaces, the effective wall distance and the automatic wall treatment are modified. The effective wall distance is modified based on the model to accurately explain the shift of velocity profile on the various roughness heights introduced by Ligrani and Moffat [11]. The automatic wall treatment suggested by Menter et al. [12] is applied to obtain the accurate wall values regardless of heights of surface roughness and near-wall grid. The distributions of skin frictions on the relatively smooth and rough circular cylinder with various Reynolds numbers are compared between the present model and Knopp et al. [5]. This study confirms that the present method yields the equivalent results with the existing model [5]. Furthermore, the present method accurately predicts the transition onset positions and peaks of skin fiction with various Reynolds numbers on a circular cylinder. In particular, the present method shows better performance for the laminar and fully turbulent flow. 
As a remaining issue, the wall boundary condition of the roughness amplifier is required to improve the accuracy for the transition onset for the relatively rough surface, since the present model assumed that the roughness amplifier linearly increases with the surface roughness height. It will be further investigated.

\section{Acknowledgments}

This work was supported by Brain Pool Program through the National Research Foundation of Korea (NRF) fu nded by the Ministry of Science and ICT (2020H1D3A1A04080407) and the EUDP (Energy Technology Development and Demonstration Program) support scheme for project IEA Task 19 (grant no. 64019-0515).

\section{References}

[1] Langtry, R. B., and Menter, F. R., “Correlation-Based Transition Modeling for Unstructured Parallelized Computational Fluid Dynamics Codes,” AIAA Journal, Vol. 47, No. 12, 2009, pp. 2894-2906. https://doi.org/10.2514/1.42362.

[2] Menter, F. R., “Two-Equation Eddy-Viscosity Turbulence Models for Engineering Applications,” AIAA Journal, Vol. 32, No. 8, 1994, pp. 1598-1605.

https://doi.org/10.2514/3.12149.

[3] Dassler, P., Kozulovic, D., and Fiala, A., "Modeling of Roughness Induced Transition Using Local Variables," V European Conference on Computational Fluid Dynamics ECCOMAS CFD 2010, Lisbon, June 2010.

[4] Langel, C. M., Chow, R., van Dam, C. P., Maniaci, D., Ehrmann, R. S., and White, E. B., "A Computational Approach to Simulating the Effects of Realistic Surface Roughness on Boundary Layer Transition,” 52nd AIAA Aerospace Sciences Meeting - AIAA Science and Technology Forum and Exposition, SciTech 2014, AIAA 2014-0234, 2014, pp. 1-16.

https://doi.org/10.2514/6.2014-0234

[5] Knopp, T., Eisfeld, B., and Calvo, J. B., “A New Extension for k- Turbulence Models to Account for Wall Roughness." International Journal of Heat and Fluid Flow, Vol. 30, No. 1, 2009, pp. 54-65. https://doi.org/10.1016/j.ijheatfluidflow.2008.09.009. 
[6] Son, C., Kelly, M., and Kim, T., "Boundary-Layer Transition Model for Icing Simulations of Rotating Wind Turbine Blades," Renewable Energy, Vol. 167, 2020, pp. 172-183.

https://doi.org/10.1016/j.renene.2020.11.070.

[7] Spalart, P. R., "Trends in Turbulence Treatments," Fluids 2000 Conference and Exhibit, AIAA-2000-2306, 2000.

https://doi.org/10.2514/6.2000-2306

[8] Durbin, P. A., Medic, G., Seo, J. M., Eaton, J. K., and Song, S., "Rough Wall Modification of Two-Layer kع," Journal of Fluids Engineering, Transactions of the ASME, Vol. 123, No. 1, 2001, pp. 16-21. https://doi.org/10.1115/1.1343086.

[9] Aupoix, B., and Spalart, P. R., "Extensions of the Spalart - Allmaras Turbulence Model to Account for Wall Roughness," International Journal of Heat and Fluid Flow, Vol. 24, No. 4, 2003, pp. 454-462. https://doi.org/10.1016/S0142-727X(03)00043-2.

[10] Nikuradse, J., “Laws of Flow in Rough Pipes,” NACA-TM-1292, Nov. 1950.

[11] Ligrani, P. M., and Moffat, R. J., "Structure of Transitionally Rough and Fully Rough Turbulent Boundary Layers," Journal of Fluid Mechanics, Vol. 162, No. 8, 1986, pp. 69-98. https://doi.org/10.1017/S0022112086001933.

[12] Menter, F. R., Ferreira, J. C., and Esch, T., "The SST Turbulence Model with Improved Wall Treatment for Heat Transfer Predictions in Gas Turbines," International Gas Turbine Congress 2003, IGTC2003-TS-059, Tokyo, Nov. 2003, pp. 1-7.

[13] Menter, F., and Esch, T., "Elements of Industrial Heat Transfer Predictions, " 16th Brazilian Congress of Mechanical Engineering (COBEM), Vol. 20, Uberlândia, Nov. 2001, pp. 117-127.

[14] Feindt, E. G., "Untersuchungen über die Abhängigkeit des Umschlages laminar-turbulent von der Oberflähenrauigkeit und der Druckverteilung,” Schiffbautechn. Gesellschaft, Vol. 50, 1956, pp. 180-203.

[15] Achenbach, E., "Total and Local Heat Transfer from a Smooth Circular Cylinder in Cross-Flow at High Reynolds Number." International Journal of Heat and Mass Transfer, Vol. 18, No. 12, 1975, pp. 13871396.

https://doi.org/10.1016/0017-9310(75)90252-5. 